\title{
PENGARUH MODIFIKASI MEDIA PEMBELAJARAN TERHADAP HASIL PEMBELAJARAN SHOOTING DALAM PERMAINAN SEPAKBOLA
}

\author{
Iif Firmana \\ STKIP Muhammadiyah Kuningan \\ email: iiffirmana@gmail.com
}

\begin{abstract}
Abstrak
Penelitian ini dilatar belakangi oleh berdasarkan survey pendahuluan dan observasi di SMP Negeri 1 Cigandamekar, tingkat ketepatan atau akurasi shooting dalam permainan sepak bola masih rendah. Adapun rumusan masalah dalam penelitian ini adalah apakah terdapat pengaruh modifikasi media pembelajaran terhadap hasil shooting dalam permainan sepak bola pada siswa putra kelas VIII SMP Negeri 1 Cigandamekar?. Tujuan penelitian ini adalah untuk mengetahui pengaruh modifikasi media pembelajaran terhadap hasil shooting dalam permainan sepakbola pada siswa putra kelas VIII SMP Negeri 1 Cigandamekar. Penelitian ini merupakan penelitian eksperimen. Populasi dalam penelitian ini adalah siswa putra kelas VIII A-VIII D SMP Negeri 1 Cigandamekar yang berjumlah 80 siswa.Teknik pengambilan sampel dengan menggunakan teknik purposive sampling . Jadi sampel pada penelitian ini adalah siswa putra kelas VIII A SMP Negeri 1 Cigandamekar yang berjumlah 15 siswa. Teknik pengumpulan data yang digunakan adalah tes menembak bola ke sasaran (shooting). Teknik analisis data dalam penelitian ini adalah uji normalitas, dan uji hipotesis yang digunakan untuk mengetahui pengaruh modifikasi media pembelajaran terhadap hasil shooting dalam permainan sepak bola pada siswa putra kelas VIII A SMP Negeri 1 Cigandamekar. Berdasarkan perhitungan secara statistik diperoleh $Z$ Hit $(13,822)>Z$ daf $(2,35)$ maka Hi yang diterima artinya terdapat pengaruh modifikasi media pembelajaran terhadap hasil shooting dalam permainan sepak bola pada siswa putra kelas VIII A SMP Negeri 1 Cigandamekar. Kesimpulan dalam penelitian ini adalah terdapat pengaruh modifikasi media pembelajaran terhadap hasil shooting dalam permainan sepak bola pada siswa putra kelas VIII A SMP Negeri 1 Cigandamekar.
\end{abstract}

Kata Kunci: Modifikasi, media, pembelajaran.

\footnotetext{
Abstract

This research is based on preliminary survey and observation in SMP Negeri 1 Cigandamekar, the level of accuracy or accounting in soccer game is still low. As the formulation of the problem in this research is whether there is influence of learning media modification to the shooting results in the game of football on the students of class VIII SMP Negeri 1 Cigandamekar?. The purpose of this study is to determine the effect of learning media on the shooting results in the game of football in the students of class VIII SMP Negeri 1 Cigandamekar. This research is an experimental research. The population in this research is the students of class VIII A-VIII D SMP Negeri 1 Cigandamekar which has 80 students. Sampling technique using purposive sampling technique. So the sample in this study is the students of class VIII SMP Negeri 1 Cigandamekar who has 15 students. Technical data used is a test shoot the ball to the target (shooting). Technique of data analysis in this research is normality test, and hypothesis test used to know influence of learning media to shoot result in
} 
game of soccer at student of class VIII SMP Negeri 1 Cigandamekar. Based on the statistical calculation of $Z$ Hit $(13,822)>Z$ daf $(2,35)$ then hai accepted there must be effect of learning media modification to shoot result in game of soccer at student of class VIII SMP Negeri 1 Cigandamekar. The conclusion in this research is a form of modification of learning media to the shooting result in the game of soccer at grade VIII students of SMP Negeri 1 Cigandamekar.

Keywords: Modification of instructional media, learning outcomes

(C) 2017 STKIP Muhammadiyah Kuningan 


\section{PENDAHULUAN}

Sepakbola merupakan salah satu cabang olahraga permainan yang diajarkan dalam pendidikan jasmani. Permainan sepakbola sudah dipelajari dari tingkat SD, SMP, SMA bahkan di universitas. Teknik dasar sepakbola yang harus dipelajari oleh peserta didik adalah passing, shooting, dribbling, dan heading. Maka setiap siswa harus bisa melakukan setiap teknik dasar yang ada dalam permainan sepakbola tersebut. Karena teknik dasar tersebut merupakan rangkaian pada saat bermain sepakbola.

Pada saat melakukan observasi di SMP Negeri 1 Cigandamekar Kecamatan Cigandamekar Kabupaten Kuningan, diketahui pelaksanaan pembelajaran sesuai dengan rencana pembelajaran yang disampaikan oleh guru. Tetapi dalam proses pembelajaran permainan sepakbola tersebut, belum menunjukan hasil yang diharapkan. Hasil belajar sepakbola meliputi passing, shooting, dribbling, dan heading. Dari keempat teknik dasar sepakbola tersebut, hasil teknik dasar shooting yang paling kurang. Hal ini bisa dilihat pada saat melakukan shooting siswa masih banyak kesulitan. Kesulitan yang dihadapi para siswa pada saat melakukan shooting yaitu perkenaan kaki kurang tepat pada bola, sehingga bola melambung keatas atau melebar kesamping sasaran. Dengan minimnya kemampuan siswa dalam melakukan salah satu teknik dasar, sehingga berdampak terhadap hasil pembelajaran permainan sepakbola.

Banyak faktor yang mempengaruhi hasil pembelajaran siswa diantaranya kemauan dari diri sendiri, giat belajar, dorongan dari orang-orang sekitar, sarana dan prasarana yang ada disekolah, kreativitas guru dalam memodifikasi media pembelajaran dan lain sebagainya. Sarana dan prasarana yang ada disetiap sekolah kebanyakan kurang memadai dan bahkan ada beberapa yang kurang layak untuk dipergunakan dalam pembelajaran. SMP Negeri 1 Cigandamekar yang berada dibagian wilayah Kuningan utara, memiliki sarana prasarana pembelajaran pendidikan jasmani olahraga dan kesehatan yang belum memadai. Keterbatasan sarana prasarana bukan menjadi penghalang seorang guru untuk memberikan materi. Tetapi dijadikan pemecut untuk mendorong guru agar kreatif dalam memodifikasi media pembelajaran. 
Menurut Ali (2005: 8) media pembelajaran memiliki beberapa karakteristik sebagai berikut Penekanan media pembelajaran terdapat pada visual dan audio, sebagai alat bantu proses pembelajaran, (2) Dapat digunakan dalam rangka komunikasi dan interaksi guru dan siswa dalam proses pembelajaran, (3) Dapat digunakan secara masal (misalnya radio, televisi), kelompok besar dan kelompok kecil (misalnya film, slide, video, OHP), atau perorangan (misalnya : modul, komputer, radio tape/ kaset, video recorder).

Modifikasi disini adalah perubahan dari keadaan lama menjadi keadaan baru. Perubahan itu dapat berupa bentuk, fungsi cara penggunaan dan manfaat tanpa sepenuhnya menghilangkan karakteristik semula. Modifikasi media pembelajaran memiliki kelebihan yaitu meningkatkan penguasaan teknik dasar, meningkat keterampilan, menumbuhkan minat dan motivasi belajar siswa, meningkatkan koordinasi gerak dalam melakukan teknik dan meningkatkan akurasi shooting. Tujuan modifikasi dalam mata pelajaran pendidikan jasmani olahraga dan kesehatan yaitu agar siswa memperoleh kepuasan dalam mengikuti pelajaran, meningkatkan keberhasilan dalam berpartisipasi dan siswa dapat melakukan pola gerak secara benar.

Modifikasi media pembelajaran dalam penelitian ini adalah memodifikasi permainan sepakbola dari jumlah pemain dan luas lapangan. Sepakbola biasanya dimainkan 11 vs 11 dan luas lapangan kurang lebih 100m x $75 \mathrm{~m}$, dimodifikasi menjadi pemain 5 vs 5 dan lapangan beukuran 40m x $20 \mathrm{~m}$. Dengan permainan modifikasi dapat memudahkan anak dalam mengikuti pembelajaran gerak, karena pembelajaran gerak ada tahapantahapannya. Selain itu permainan modifikasi membuat anak senang dan tereksploitasi kemampuan gerak dan kognitifnya. Berdasarkan pendahuluan diatas, maka peneliti mengadakan sebuah penelitian dengan judul Manfaat Modifikasi Media Pembelajaran Terhadap Hasil Pembelajran Shooting Dalam Permainan Sepakbola di SMP Negeri Cigandamekar.

\section{METODE}

Metode yang digunakan dalam penelitian ini adalah metode eksperimen. Metode eksperimen adalah suatu cara untuk mecari hubungan sebab akibat antara dua faktor yang sengaja ditimbulkan oleh si peneliti 
dengan menghilangkan faktor-faktor yang mengganggu. Dengan menghilangkan faktor-faktor yang menggangu, si peneliti akan lebih fokus terhadap objek yang ditimbulkannya.
Dan penelitiannya akan lebih terarah dan terkontrol lagi. Sedangkan desain penelitiannya dengan one group preetest posttest design/kontrol grup yang tidak menerima perlakuan.

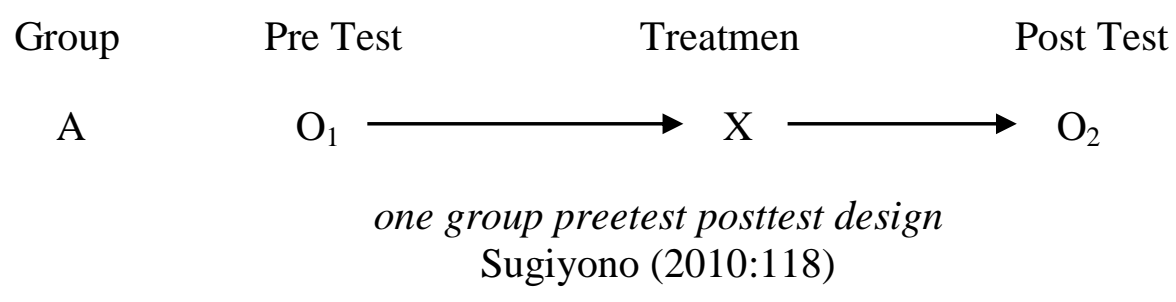

Populasi merupakan suatu Instrumen penelitian adalah tes kumpulan manusia, benda, peristiwa atau kejadian yang dapat memberikan data dan informasi, serta memiliki kuantitas atau kualitas dan karakteristik tertentu yang sesuai dengan masalah yang diteliti untuk dipelajari, dan kemudian ditarik kesimpulannya. Populasi pada penelitian ini adalah siswa putra kelas VIII A-VIII B SMP Negeri 1 Cigandamekar yang berjumlah 80 siswa. Adapun sampel adalah hasil penarikan sebagian dari populasi untuk mewakili seluruh populasi yang ditentukan. Teknik pengambilan sampel dengan menggunakan teknik purposive sampling. Sampel pada penelitian ini adalah siswa putra kelas VIII A SMP Negeri 1 Cigandamekar yang berjumlah 15 siswa. menembak bola ke sasaran (shooting) yang bertujuan untuk mengukur keterampilan, ketepatan dan kecepatan gerak kaki dalam menyepak bola ke sasaran. Menurut Nurhasan (2007:82) Alat yang digunakan adalah bola, stopwatch, gawang, nomor-nomor dan tali. Prosedur pelaksanaan adalah

a. Testee berdiri di belakang yang diletakkan pada sebuah titik berjarak 11 meter di depan gawang / sasaran.

b. Pada saat kaki testee mulai menendang bola maka stopwatch dijalankan dan berhenti saat bola mengenai sasaran.

c. Testee diberi 3 kali kesempatan.

d. Gerakan dianggap gagal apabila bola keluar dari daerah sasaran dan menempatkan bola tidak pada jarak 11 meter. 
e. Cara penskoran adalah jumlah skor dan bila bola kena tali sasaran maka dan waktu yang ditempuh bola pada diambil skor terbesar. sasaran dalam 3 kali kesempatan

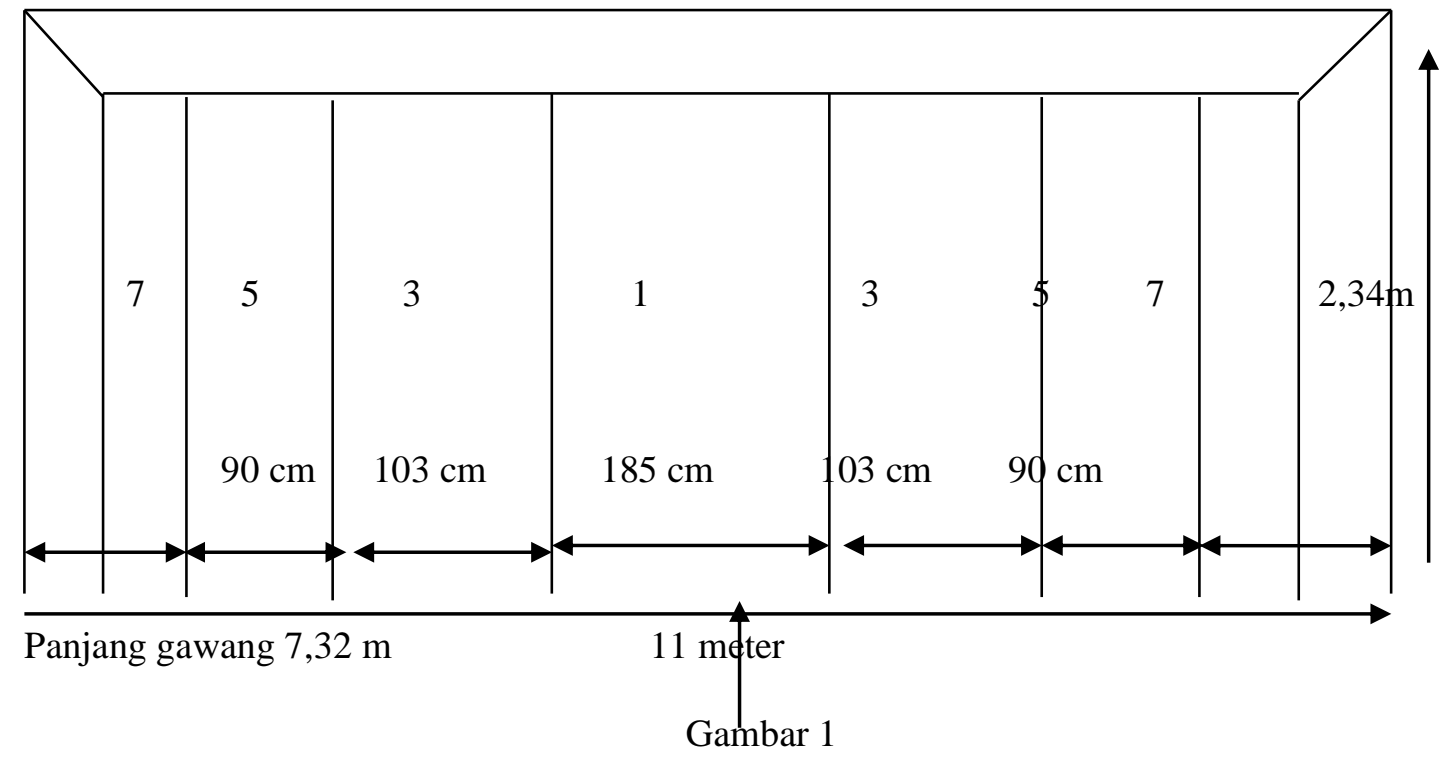

Lapangan untuk Tes Tendangan Penalti

(Nurhasan, 2007: 149)

\section{HASIL PENELITIAN}

Berdasarkan pengolahan dan analisis data hasil pretesthasil shooting dalam permainan sepak bola sebelum menggunakan modifikasi media pembelajaran pada siswa putra kelas VIII A $\quad$ SMP Negeri 1 Cigandamekarmemperoleh nilai terendah 3, nilai tertinggi 12 dan memperoleh rata-rata sebesar 6,533. Hal ini membuktikan bahwa hasil shooting dalam permainan sepakbola sebelum menggunakan modifikasi media pembelajaran pada siswa putra kelas VIII A SMP Negeri 1 Cigandamekar masih rendah dengan jarak interval 5 10.

Sedangkan pengolahan dan analisis data hasil posttesthasil shooting dalam permainan sepak bola setelah menggunakan modifikasi media pembelajaran pada siswa putra kelas $\begin{array}{lllll}\text { VIII A } & \text { SMP Negeri } 1\end{array}$ Cigandamekarmemperoleh nilai terendah 12, nilai tertinggi 21 dan memperoleh rata-ratasebesar 16,533 . Hal ini membuktikan bahwa hasil shooting dalam permainan sepak bola setelah menggunakan modifikasi media pembelajaran pada siswa putra kelas VIII A SMP Negeri 1 Cigandamekar 
termasuk kategori tinggidengan jarak interval $16-21$.

Perhitungan secara statistik diperoleh Z Hit $(13,822)>Z$ daf $(2,35)$ maka Hi yang diterima artinya terdapat pengaruh yang signifikan modifikasi media pembelajaran terhadap hasil shooting dalam permainan sepak bola pada siswa putra kelas VIII A SMP Negeri 1 Cigandamekar. Hipotesis yang menyatakan terdapatpengaruh yang signifikan modifikasi media pembelajaran terhadap hasil shooting dalam permainan sepak bola pada siswa putra kelas VIII A SMP Negeri 1 Cigandamekar dapat diterima dengan taraf kepercayaan $(0,05)$.

Dari sudut pandang penyerangan, tujuan sepak bola adalah melakukan shooting ke gawang. Seorang pemain harus menguasai keterampilan dasar menendang bola dan selanjutnya mengembangkan sederetan teknik shooting dan mencetak gol dari berbagai posisi di lapangan.Menendang bola merupakan pola gerak dominan yang paling penting dalam permainan sepak bola. Pada dasarnya bermain sepak bola itu tidak lain dari permainan menendang bola. Shooting atau tembakan merupakan salah satu cara untuk memasukkan bola atau menciptakan gol ke gawang lawan dengan menggunakan kaki sebagai subyek geraknya. "Menendang atau shooting adalah teknik dasar permainan sepak bola menendang bola yang bertujuan untuk mengumpan (passing) dan menembak kearah gawang (shooting at the goal)“.

Kesimpulannya adalah bahwa permainan modifikasi adalah perubahan dalam permainan baik itu teknik, alat, dan peraturan menjadi lebih sederhana sesuai dengan aspek perkembangan anak, tanpa menghilangkan karakteristik dari permainan tersebut. Dengan permainan modifikasi dapat memudahkan anak dalam mengikuti pembelajaran gerak, karena pembelajaran gerak ada tahapantahapannya. Selain itu permainan modifikasi membuat anak senang dan tereksploitasi kemampuan gerak dan kognitifnya.

\section{SIMPULAN}

Berdasarkan hasil pengolahan data dan pembahasan tentang pengaruh modifikasi media pembelajaran terhadap hasil shooting dalam permainan sepak bola pada siswa putra $\begin{array}{lllll}\text { kelas VIII A } & \text { SMP Negeri } 1\end{array}$ Cigandamekar, maka penulis menarik kesimpulan sebagai berikut : terdapat 
pengaruh yang signifikan modifikasi media pembelajaran terhadap hasil shooting dalam permainan sepakbola pada siswa putra kelas VIII A SMP Negeri 1 Cigandamekar dengan penggunaan modifikasi media pembelajaran, hal ini berdasarkan perhitungan secara statistik diperoleh $\mathrm{Z}$ Hit $(13,822)>\mathrm{Z}$ daf $(2,35)$ maka Hi yang diterima. Hipotesis yang menyatakan terdapatpengaruh yang signifikan modifikasi media pembelajaran terhadap hasil shooting dalam permainan sepakbola pada siswa putra kelas VIII A SMP Negeri 1 Cigandamekar dapat diterima dengan taraf kepercayaan $(0,05)$.

\section{DAFTAR PUSTAKA}

Achmadi, "pendidikan Jasmani dan Olahraga", Jakarta, Rineka Cipta, 2007

Arikunto, Suharsimi, "Prosedur Penelitian, Suatu Pendekatan Praktek", Jakarta, Pustaka Setia, 2013

Hadi, Sutrisno, "metode Penelitian", Bandung, Remaja Rosda Karya, 2010

Heryana, Dadan, "Olahraga dan Kesehatan untuk Siswa SD Kelas $V$ ' Jakarta, Pusat Perbukuan, 2010

Indarto. 2009.

PelatihanKomponenKondisiFisi $k$. Jakarta:RinekaCipta.

Juari. 2010. Olahraga dan Kesehatan untuk Siswa SD Kelas VI. Jakarta : Pusat Perbukuan.
Latuheru. Permainan Sepakbola”, Jakarta, Pustaka Setia, 2005

Moeljono,

"TeknikDasarPermainanSepak

Bola", Surabaya, Kartika, 2008

Muhammad. 2009. Metode Statistika. Bandung : Pustaka

Nasir, Muhammad. 2013. Metode Statistika. Bandung : Pustaka

Nurdin, 2010, "Permainan Bola Besar", Yogyakarta : Kanisiu

Nurgana, Endi, "Statistika untuk Penelitian", Bandung, Tarsito, 2007

Nurhasan, “Teknik Pengukuran”, Jakarta, Pustaka Setia, 2007

Ramadan, G. (2017). Pengaruh Metode Pembelajaran Dan Motivasi Belajar Terhadap Hasil Belajar Passing Sepakbola. JUARA : Jurnal Olahraga, 2(1), 1-10. Retrieved from

http://jurnal.upmk.ac.id/index.php/j uara/article/view/27

Sajoto, Teknik Permainan Bola Besar, Semarang, FKIP UNNES, 2010

Soekatamsi, "PermainanSepakbola", Jakarta, Pustaka Setia, 2008

Subroto, Toto, "Permainan Bola Besar", Yogyakarta, Kanisius, 2001

Sugiono, "Statistik untuk penelitian", Bandung, Alfhabeta, 2010

Sujana, Nana, "Metode Statistika", Bandung, Tarsito, 2011

Sulardi, "Permainan Bola Besar", Yogyakarta, Kanisius, 2008

Surakhman, Winarno, "Statistik untuk Penelitian", Surabaya, Kartika, 2008.

Suwarso, "Olahraga dan Kesehatan untuk Siswa SD Kelas IV', Jakarta, Pusat Perbukuan, 2010

Wagino, "Olahraga dan Kesehatan untuk Siswa SD Kelas III", Jakarta, Pusat Perbukuan, 2010 
Wahyudi, Yudi, "Pembelajaran Penjas di Sekolah Dasar", Jakarta, Raja GrafindoPersada, 2008
Yunus. Teknik Permainan Bola Besar, Semarang, FKIP UNNES, 2010 